\title{
The Second Case of Death in the Same Family from Chronic Renal Failure and Systemic Oxalosis as a Result of Primary Hyperoxaluria Type 1
}

\author{
Jamal Qasem Abumwais
}

Ministry of Education and Higher Education, Jenin, Palestine

\begin{abstract}
Background: Primary hyperoxaluria is a rare cause of chronic renal failure in children worldwide, but it is an important cause of chronic renal failure among children under 15 years old in Jenin district (Palestine) contributing about $67 \%$ of the causes of chronic renal failure among these children as was found in a previous study. The infantile form of hyperoxaluria manifests early with nephrocalcinosis and leads to end-stage renal failure in early childhood and the most severe form may lead to death during the first year of life.

Case presentation: We report the case of a 8-years old boy with a history of primary hyperoxaluria type1 since the age of three months presented with ascites, generalized edema, fever, myopathy, limited movement ability, general malaise, severe malnutrition, and respiratory difficulties. Clinical, laboratory, ultrasound, cardiac investigations revealed end-stage renal failure accompanied by heart failure, liver failure, liver cirrhosis, and systemic oxalosis. The patient was in a bad condition, stayed 4 days in the ICU and died in the fourth day from complications of systemic oxalosis.

Conclusion: History revealed that this is the second case of death in the same family from ESRD and complications of primary hyperoxaluria. The first death was for his brother since about 10 years who died at age of three months. It seems that the primary hyperoxaluria type 1 in this family is very severe and leads to end-stage renal disease and systemic oxalosis in early childhood despite conservative treatment. Since, sometimes, there are more than one case of primary hyperoxaluria in the same family, all children in the family with a history of primary hyperoxaluria - even who looks like healthy - must be screened for the disease because early diagnosis is important in treating strategies and delaying complications such as end-stage renal disease and systemic oxalosis.
\end{abstract}

Keywords: Systemic oxalosis; Jenin district; Palestine; Primary hyperoxaluria type 1; Chronic renal failure

\section{Introduction}

The primary hyperoxalurias are autosomal recessive disorders resulting from deficiency of hepatic alanine:glyoxylate aminotransferase(PH I ) or D-glycerate dehydrogenase/glyoxylate reductase (PH II) [1]. Type II hyperoxaluria (PH II) is much rarer disorder than type I (PH I) [2]. The severity of the disease expression is greater in type I primary hyperoxaluria than in type II [1]. Marked hyperoxaluria results in urolithiasis, renal failure, and systemic oxalosis [1]. The infantile form manifests early with nephrocalcinosis and leads to end-stage renal failure in childhood [3]. The most severe form may lead to death during the first year of life [3].

Once the disease has been diagnosed before the onset of renal failure, it is treated conservatively. The conservative treatment includes high fluid intake, pyridoxine and crystallization inhibitors [4]. The conservative treatment is not the best matter of choice. Recently, the cure of the metabolic defect can be achieved only by liver transplantation before renal damage and by combined hepato-renal transplantation for patients with end-stage renal failure $[4,5]$.

We here report a child patient who died from end-stage renal failure and Systemic Oxalosis as a Result of Primary hyperoxaluria type 1.

\section{Case Presentation}

A 8-years child male with a history of primary hyperoxaluria type 1 since 3-month age who was treated conservatively since that time, was presented to the intensive care unit (ICU) of The Martyr Dr. Khalil Sulaiman Hospital in Jenin city in 11/6/2012 suffering from chronic renal failure. At admission, history and first clinical evaluation revealed anorexia, wasted muscles with limited movement ability since 2 years, decrease level of consciousness, ascites, generalized edema since 2 weeks duration, fever, but there was no cough, no vomiting, no diarrhea . After that, cardiac, laboratory, clinical, X- ray, and ultra- sound examinations revealed chronic renal failure with systemic oxalosis, liver failure and cirrhosis, heart failure, tachypnea, respiratory distress, and hypotension.

During the following three days (12/6-14/6/2012), the patient continued suffering from marked tachypnea, marked respiratory distress and persistent hypotension not responding to IVF admission. Laboratory findings during the four days of hospitalization are summarized in Table 1.

The patient died in 14/6/2012 at 7:15 P.M before initiation of hemodialysis because he was in a bad condition which can't permit to begin hemodialysis. The cause of death was cardiopulmonary arrest due to acute respiratory failure caused by systemic oxalosis, renal failure, and liver cirrhosis.

\section{Discussion}

This case is the second death case in the same family (which have 6 children: 3 males and 3 females in addition to the two deaths) from complications of systemic oxalosis caused by primary hyperoxaluria type 1. Family history revealed the death of his brother from the same disease at age of three months, this occurred since 10 years. The parents are well but niece of the father had the disease and died from

*Corresponding author: Jamal Qasem Abumwais, Ministry of Education and Higher Education, Jenin, Palestine, Tel: 0097242518312, 00972599072538 E-mail: jamal_abumwais@yahoo.com

Received October 29, 2013; Accepted December 16, 2013; Published December 18,2013

Citation: Abumwais JQ (2013) The Second Case of Death in the Same Family from Chronic Renal Failure and Systemic Oxalosis as a Result of Primary Hyperoxaluria Type1. Genetics 2: 121. doi:10.4172/2161-1041.1000121

Copyright: (c) 2013 Abumwais JQ. This is an open-access article distributed unde the terms of the Creative Commons Attribution License, which permits unrestricted use, distribution, and reproduction in any medium, provided the original author and source are credited. 
Citation: Abumwais JQ (2013) The Second Case of Death in the Same Family from Chronic Renal Failure and Systemic Oxalosis as a Result of Primary Hyperoxaluria Type1. Genetics 2: 121. doi:10.4172/2161-1041.1000121

Page 2 of 2

\begin{tabular}{|c|c|c|c|c|c|}
\hline Lab.Test & $\begin{array}{c}11 / 6 / 2012 \\
\text { (Before treatment) }\end{array}$ & $\begin{array}{c}11 / 6 / 2012 \\
\text { (After treatment) }\end{array}$ & $12 / 6 / 2012$ & $13 / 6 / 2012$ & $14 / 6 / 2012$ \\
\hline WBC (K/UI) & 7.7 & - & 6.4 & 9.4 & 11.1 \\
\hline RBC (M/UI) & 2.34 & 2.71 & 2.77 & 3.67 & 3.4 \\
\hline HGB (g/dl ) & 5.9 & - & 7.3 & 10.2 & 9 \\
\hline HCT ( \% ) & 19 & - & 23 & - & - \\
\hline $\mathrm{MCV}(\mathrm{FI})$ & 81 & - & 82 & - & - \\
\hline Platelets (K/UI) & 119 & - & 114 & 91 & 86 \\
\hline PT & 16 & - & 15 & - & - \\
\hline PTT & 32 & - & 37 & - & - \\
\hline Glucose (mg/dl) & 117 & 115 & 110 & 131 & 130 \\
\hline Total protein Crest $(\mathrm{g} / \mathrm{dl})$ & 2.4 & 6.6 & - & 4.7 & - \\
\hline Albumin (g/dl) & - & 3.2 & - & 3.1 & - \\
\hline Creatinine (mg/dl) & 5.5 & - & 5.2 & 5.1 & 4.9 \\
\hline BUN (mg/dl ) & - & - & 176 & 157 & 144 \\
\hline Alk.Phosphatase (U/L ) & 398 & - & - & - & - \\
\hline $\mathrm{ALT}(\mathrm{GPT})(\mathrm{U} / \mathrm{L})$ & 13 & - & - & - & - \\
\hline AST (GOT) (U/L ) & 34 & - & - & - & - \\
\hline $\mathrm{Na}(\mathrm{mg} / \mathrm{l})$ & 136 & - & 141 & 144 & 136 \\
\hline $\mathrm{K}(\mathrm{mg} / \mathrm{l})$ & 4.8 & - & 3.9 & 3.8 & 4.0 \\
\hline Ca- free $(\mathrm{mg} / \mathrm{dl})$ & 0.91 & - & 0.89 & 0.97 & 1.03 \\
\hline $\mathrm{PH}$ & - & - & - & - & 7.03 \\
\hline
\end{tabular}

Table 1: Laboratory findings of the patient during the four days of hospitalization are summarized in table.

its complications. The parents of the patient are cousins (their mothers are sisters).

The conservative treatment of this patient directly after diagnosis of the disease (onset of the first symptoms) delay the progression to endstage renal disease until the 8th year of life, on the other hand, his first brother didn't take any treatment and died at an early age ( 3 months) from end-stage renal disease and systemic oxalosis.

It seems that the primary hyperoxaluria type 1 in this family is from the severe infantile form that appears from birth or few months after birth and leads to end-stage renal disease in early childhood before the age of 10 years, sometimes 15 years, and mostly before the age of 20 years old despite conservative treatment (as happened with our patient) or may lead to death in the first year of life if lifted untreated (as happened with the brother of our patient). These results are similar to what was concluded in many other studies [2,3,6-9].

No preemptive liver transplantation operation has been done in the literature of patients of primary hyperoxaluria in Jenin district, this is due to many reasons, among these are un-awareness of the nature of the disease and it's complications by the family, late or wrong diagnosis by some physicians, financial burden since this operation is unavailable in Palestine and sometimes there is more than one patient in the same family.

\section{Conclusion}

In conclusion, it seems that soon or later, the primary hyperoxaluria patients in Jenin district will reach end-stage renal disease even with conservative treatment, and thus the conservative treatment (which includes hydration, high doses of pyridoxine, and crystallization inhibitors) can only delay reaching to end-stage renal disease, and thus preemptive liver transplantation or combined liver-kidney transplantation are the best matters of choice depending on renal function and patient's state at diagnosis.

Since- sometimes - there is more than one child suffering from primary hyperoxaluria in the same family, all children of the family with a history of primary hyperoxaluria - even who looks like healthy must be screened for the disease because early diagnosis is important in treating the disease and delaying complications such as end-stage renal disease and systemic oxalosis, so we recommend that all the children of this family must be screened for primary hyperoxaluria especially the newborns.

\section{Acknowledgements}

I am greatly indebted to Palestinian Ministry of Health and to Dr. Mohammad Abu-Ghali, the director of The Martyr Dr. Khalil Sulaiman Hospital who gave me the chance to do this study. Special thanks to all the physicians of the ICU and kidney unit and to all the workers in the laboratory department for their support.

\section{References}

1. Milliner DS, Wilson DM, Smith LH (2001) Phenotypic expression of primary hyperoxaluria: comparative features of types I and II. Kidney Int 59: 31-36.

2. Sanjad SA, Al-Abbad A, Al-Sabban E (1999) Primary hyperoxaluria type 1: An underestimated cause of nephrocalcinosis and chronic renal failure in Saudi Arabian children. Ann Saudi Med 19: 4-7.

3. Cochat P, Bucourt M, Daudon M, di Maio M, Benoliel G. (1996) Unusual presentation of primary hyperoxaluria in a newborn. Journal of Nephrology 9:291-292.

4. Cochat P, Gaulier JM, Koch Nogueira PC, Feber J, Jamieson NV, et al. (1999) Combined liver-kidney transplantation in primary hyperoxaluria type 1. Eur $\mathrm{J}$ Pediatr 158 Suppl 2: S75-80.

5. Kemper MJ (2005) The role of preemptive liver transplantation in primary hyperoxaluria type 1. Urol Res 33: 376-379.

6. Al-Eisa AA, Samhan M, Naseef M (2004) End-stage renal disease in Kuwait children: an 8-year experience. Transplant Proc 36: 1788-1791.

7. Rinat C, Wanders RJ, Drukker A, Halle D, Frishberg Y (1999) Primary hyperoxaluria type I: a model for multiple mutations in a monogenic disease within a distinct ethnic group. J Am Soc Nephrol 10: 2352-2358.

8. Gargah T, Khelil N, Youssef G, Karoui W, Lakhoua MR, et al. (2012) Primary hyperoxaluria type 1 in Tunisian children. Saudi J Kidney Dis Transpl 23: 385390

9. Orazi C, Picca S, Schingo PM, Fassari FM, Canepa G (2009) Oxalosis in primary hyperoxaluria in infancy: Report of a case in a 3-month-old baby. Follow-up for 3 years and review of literature. Skeletal Radiol 38: 387-391. 